\title{
Ongoing research on the pumping-induced land deformation in the Aguascalientes Valley: an analysis of the recent data of vertical deformation, groundwater level variations and local seismicity
}

\author{
Martin Hernandez-Marin ${ }^{1}$, Ruben Esquivel-Ramirez ${ }^{2}$, Mario Eduardo Zermeño-De-Leon ${ }^{1}$, \\ Lilia Guerrero-Martinez ${ }^{1}$, Jesus Pacheco-Martinez ${ }^{1}$, and Thomas J. Burbey ${ }^{3}$ \\ ${ }^{1}$ Departamento de Geotecnia e hidráulica, Universidad Autónoma de Aguascalientes, \\ Aguascalientes, Ags. 20131, Mexico \\ ${ }^{2}$ Instituto Nacional de Estadistica y Geografía, Héroe de Nacozari Sur 2301, \\ Aguascalientes, Ags., 20266, Mexico \\ ${ }^{3}$ Department of Geosciences, Virginia Tech, Blacksburg, VA, USA \\ Correspondence: Martin Hernandez-Marin (mhernandez@correo.uaa.mx)
}

Published: 22 April 2020

\begin{abstract}
In the Aguascalientes valley, middle Mexico, the demand of groundwater from the local aquifer system was suddenly increased after the late 1970s. Since then, several related problems have been occurring or become critical such as land subsidence, ground fissuring, and low-magnitude earthquakes. The most recent data of vertical deformation from PSInSAR, groundwater levels, and earthquakes, has provided critical information regarding the relationship amongst all these processes. In particular, that related to land subsidence, earth fissuring and seismicity. Regarding this, more satellite imagery and data from GPS stations are being revised as a possibility of a more generalized vertical deformation derived with low-magnitude seismicity. A particular seismic event recorded on 6 April 2019 has revealed critical information on the close association between vertical displacements occurred in active faults and low-magnitude seismic events.
\end{abstract}

\section{Introduction}

Land Subsidence and associated ground fissuring have been occurring in Aguascalientes valley over the last five decades (Aranda-Gómez, 1989). As a direct consequence of these two processes, several damages in urban and rural infrastructure have been reported (Pacheco-Martínez et al., 2013). The intensive pumping resulting from an increasing need of water for human activities is considered as the triggering cause of land deformation, while the last tectonic activity can be considered as an important conditioning factor for earth fissuring, since recent observations suggest that several ancient buried faults are being reactivated by land subsidence (Hernandez-Marin et al., 2015). GPS and satellite InSAR techniques have been used for measuring land subsidence since the early 2000s. In fact, the latest records of surface deformation correspond to TerraSAR-X and Sentinel-1 images, which were processed with InSAR techniques (INEGI, 2015). On the other hand, the recent occurrence of local seismicity has been suggested to be associated to subsidenceinduced faulting, due mainly to the increase of local earthquakes after the 1980s, which corresponds to first reports of damages in constructions by faulting. In this context, Lermo et al. (1996), analysed the records of local earthquakes using the national seismic net. They identified 18 local events between 1988 and 1994. Particularly, between 1993 to 1994, using a local seismic net of 6 stations, 5 additional events were recorded, all of them with epicenter inside or adjacent to the city of Aguascalientes, in locations close to the locally named Oriente fault (UNAM-SOP, 1994). Despite the current critical descent of groundwater levels, the relationship between cones of groundwater and maximum land sub- 


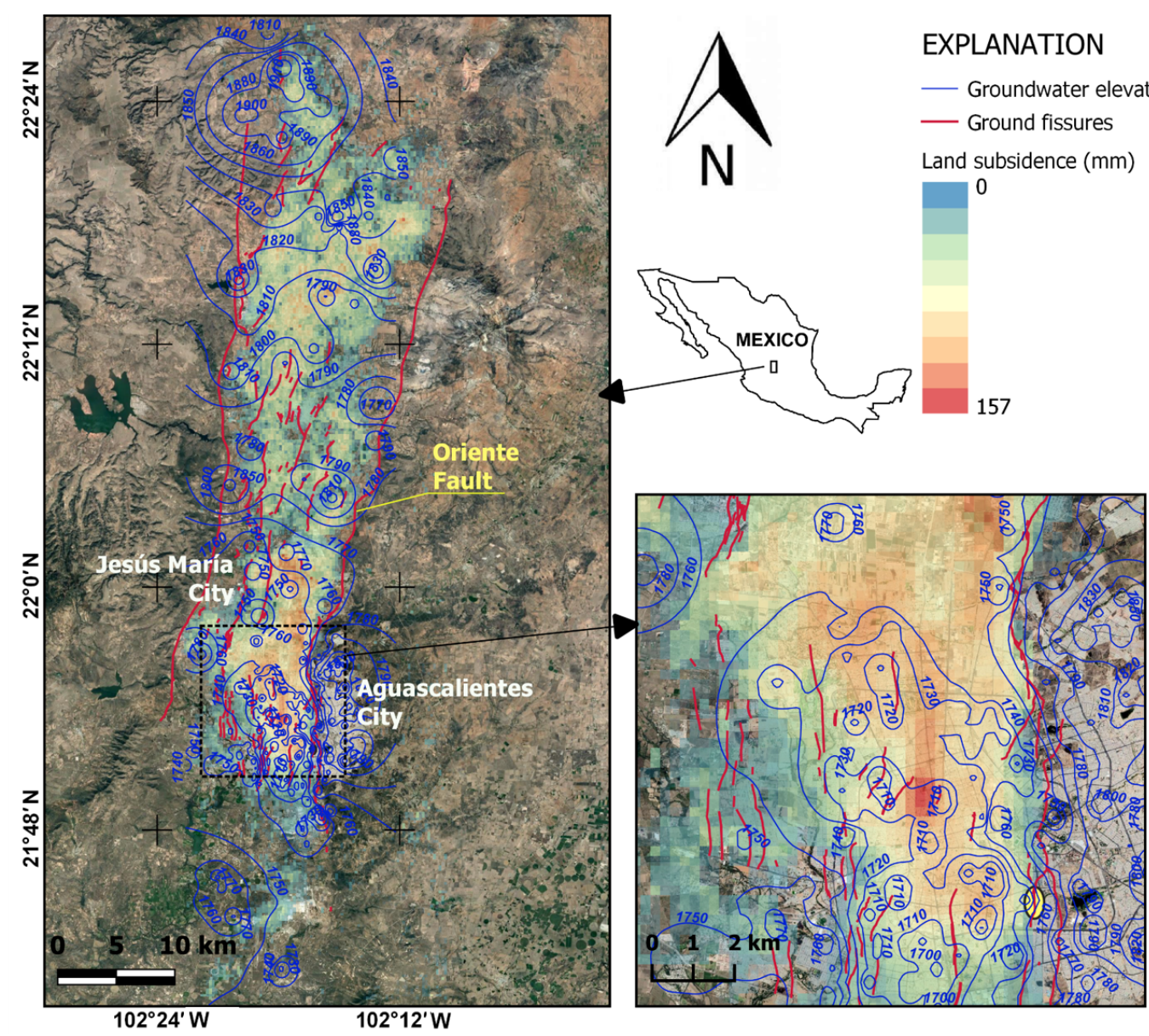

Figure 1. Land subsidence, earth fissuring and water level elevation in the valley of Aguascalientes after 2017. Figure based in a $\odot$ Google Earth complement inside Qgis.

sidence is not clear, likely due to the complexity of the involved factors (i.e. multiple-layer stratigraphy, spatially and temporally variable pumping, increasing loads due to constructions, among others). However, it is a fact that critical groundwater depletion cones are located in zones of maxim number of fault and fissures, this is, in zones where differential subsidence is critical. More detailed investigation needs to be carried out in order to establish the real correlation between cones of groundwater depletion and land deformation. The goal of this work is to compare the present land deformation with recent seismicity and determine a potential correlation between these two processes. Besides, to find a potential relationship between land deformation to critical descents of groundwater levels.

\section{Land deformation, seismicity and groundwater depletion}

Land subsidence in the valley of Aguascalientes occurred since the early 1980s and currently, some zones are observed with more than a meter and a half of accumulated deforma- tion. As shown in Fig. 1, the present deeper subsidence bowls are occurring in the urban areas of Aguascalientes and Jesus María, which is an adjacent municipality to the city of Aguascalientes. However, several minor zones of high subsidence are observed at the north, mainly due to the high volume of groundwater extraction for agriculture. As observed a maximum record of $157 \mathrm{~mm}$ during 2017, and all the deformation is concentrated between the two major normal faults. Also, in Fig. 1 can be noticed that the groundwater levels present the major cone of depletion in the zone of the Aguascalientes city, and that the groundwater flows in a north-tosouth direction.

\section{Methodology}

The overall methodology was carried out by (a) analyzing images of PSInSAR processed in both sequences, ascending and descending; (b) revising the records of seismic events; (c) positioning the epicenters of local earthquakes; and (d) analyzing the groundwater levels in order to establish the critical cones of depletion. 


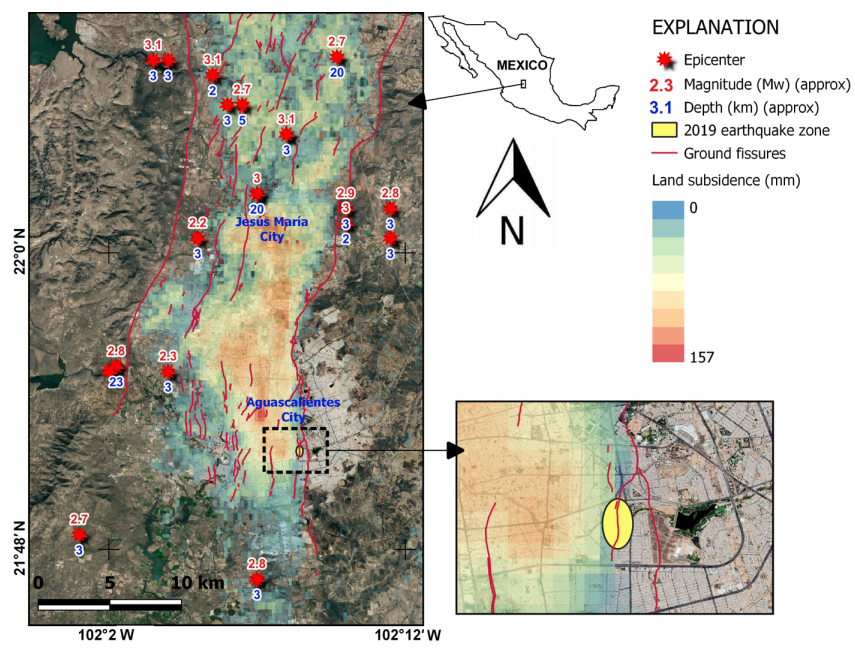

Figure 2. Location of earthquakes epicenters recorded from April 2014 to August 2017, along with the potential location of the seismic event recorded in April 2019. Magnitude (in $M_{\mathrm{W}}$ ) and depth of the earthquakes were reported by the National Seismic Survey. Figure based in a () Google Earth complement inside Qgis.

PSInSAR images revised correspond to a time-lapse from May 2016 to April 2019, in order to obtain the linear velocity of land subsidence. In addition, local seismicity was revised from the historic records of earthquakes from 2014 to 2017. However, a particular seismic event occurred in 6 April 2019 was used as base to demonstrate the correlation between seismicity and land deformation. Images form PSInSAR were revised before and after that particular earthquake. Finally, to establish the configuration of the piezometry, 216 production wells spatially distributed along the valley were used to measure the groundwater levels.

\section{Seismicity and earth fissuring}

Part of the recent seismicity occurred within or close to the Aguascalientes valley was suggested to be caused by residual tectonism (Aranda-Gómez, 1989), However, due to reports of local shaking movements from residents of the Aguascalientes city , the suspicion of a close relationship between sudden vertical displacement and low-intensity earthquakes was increased in recent years. Recently, due to the continue monitor program of land deformation from the government agency INEGI and to the recent map of faults and fissures published from SIFAGG (2009), which is coordinated by the local government, was possible to detect potential subsided zones caused directly by fault displacements and a consequent low-intensity earthquake. Figure 2 shows the occurrence of earthquakes (epicenters) inside the valley from 2014 to 2017, as well as the areas where the seismic event occurred in 6 April 2019 was sensed by inhabitants of the SE of Aguascalientes city. The location was determined based on the reports of local residents. The further analysis of this

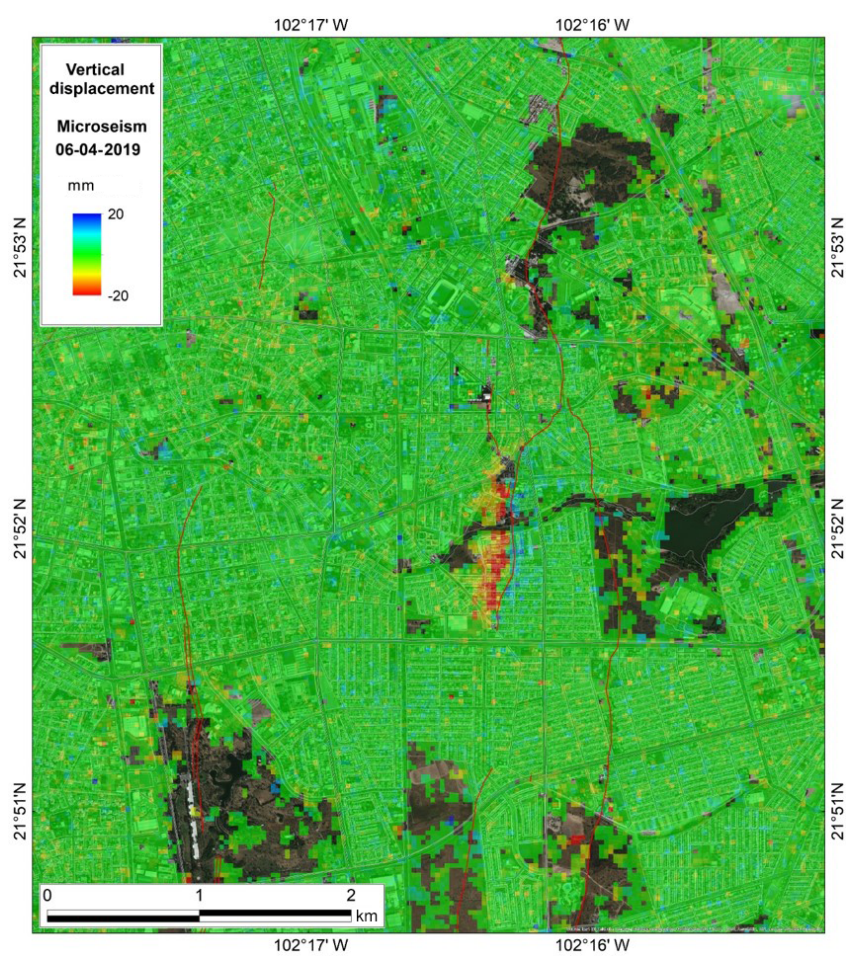

Figure 3. Vertical displacement recorded with PSI associated to the microseism of 6 April 2019. Bar scale is in millimeters. Red lines indicate the location of discontinuities. This figure was supported by the $($ Google Earth software.

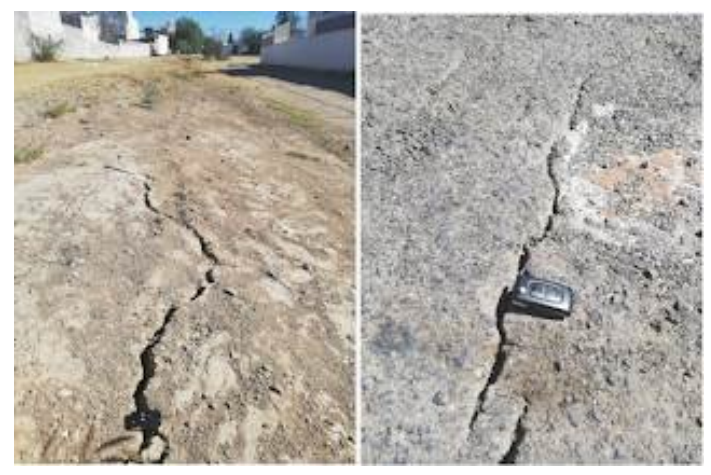

Figure 4. Fissures associated to the earthquake occurred in 6 April 2019.

event demonstrated the close relation between land subsidence, earth fissuring and seismicity, since, as observed, the deformation area is adjacent to an earth fissure branch of the Oriente fault.

Figure 3 shows the vertical deformation occurred after the earthquake of 6 April 2019. Deformations in this figure were computed from Sentinel-1 ascending (5-17 April 2019) and descending (2-14 April 2019). Results were derived from PSInSAR general processing of ascending/descending datasets of images acquired from May 2016 to April 2019. In 
order to extract only the earthquake signal, the effect of constant linear deformation of subsidence was subtracted using the mean velocity calculated from the PSInSAR ascending and descending trajectories. That figure shows a maximum vertical deformation that is concentrated adjacent to a branch of the Oriente fault. Vertical sinking is close to $20 \mathrm{~mm}$ and concentrated on the west (hanging wall) while some points of uplift are recorded in similar magnitude to sinking on the east (footwall). This ascent-descent mechanical behavior of the surface was previously recorded for another branch of the Oriente fault (Hernandez-Marin et al., 2017), Although that record did not was associated to any seismic event. Figure 4 depicts some fissures produced with the 6 April microseism found during field observations on the same day of the event.

\section{Summary and conclusions}

This investigation suggests a close relation between fissuring, land subsidence and low-magnitude seismicity. However, the relationship between groundwater withdrawal and land subsidence or earth fissuring remains with unanswered questions due to the large number of factors involved. A considerable number of low-magnitude earthquakes are occurring in recent years in the valley of Aguascalientes, most of them are recorded within the valley at relatively shallow depths. The vertical deformation associated to a seismic event recorded in 4 April 2019 was monitored and analyzed using PSInSAR and a dataset of images before and after that date. In accordance with field work, which included the opinion of local residents, the microseism was mostly sensed in a zone currently affected by a fault that seems to be a branch of the Oriente fault, one of the most active and prominent surface discontinuities in the valley of Aguascalientes. The vertical deformation includes surface sinking and uplift, both of them with a magnitude close to $20 \mathrm{~mm}$. Surface sinking was recorded on the west (hanging wall), while uplift occurred on the east (footwall). Despite the evidence presented here, more research needs to be performed in order to define the relationship among land subsidence, earth fissuring, local seismicity and groundwater withdrawal.

Data availability. Data of epicenters and their main features are under shelter of the National Seismic Survey, to get access to them, anybody must complete an official request. Deformation data were obtained from Sentinel-1, whose data are freely provided by ESA through Copernicus Programme and were downloaded from the Alaska Satellite Facility (https://www.asf.alaska.edu/sentinel/, last access: 4 April 2019).

Author contributions. MHM prepared and edited the manuscript, including the figures; integrated and analyzed most of the information; coordinated all coauthors' contributions. RER analyzed the deformation data and its geospatial distribution.
MEZDL and LGM provided the seismic and groundwater level data, respectively, as well as their geospatial distribution. JPM and TJB collaborated with the preparation and organization of the manuscript.

Competing interests. The authors declare that they have no conflict of interest.

Special issue statement. This article is part of the special issue "TISOLS: the Tenth International Symposium On Land Subsidence - living with subsidence". It is a result of the Tenth International Symposium on Land Subsidence, Delft, the Netherlands, 17-21 May 2021.

Acknowledgements. The authors are thankful for the reviewer's comments, which significantly improved the quality of this paper.

\section{References}

Aranda-Gómez, J. J.: Geología preliminar del graben de Aguascalientes, Rev. Mex. Cienc. Geol., 8, 22-32, 1989.

Hernández-Marín, M., González-Cervantes, N., Pacheco-Martínez, J., and Frías-Guzmán, D. H.: Discussion on the origin of surface failures in the Valley of Aguascalientes, México, Proc. IAHS, 372, 235-238, https://doi.org/10.5194/piahs-372-2352015, 2015.

Hernández-Marín, M., Pacheco-Martínez, J. Burbey, T. J., CarreónFreyre, D. C., Ochoa-González, G. H., Campos-Moreno, G. E., and de-Lira-Gómez, P.: Evaluation of subsurface infiltration and displacement in a subsidence-reactivated normal fault in the Aguascalientes Valley, Mexico, Environ. Earth Sci., 76, 812, https://doi.org/10.1007/s12665-017-7163-y, 2017.

Inegi: Estudio de los Hundimientos por Subsidencia en Aguascalientes con Métodos Satelitales, Reporte Técnico, Subsidencias No. 1, 2015.

Lermo, J., Nieto-Obregón, J., and Zermeño, M.: Faults and fractures in the valley of Aguascalientes. Preliminary microzonification, Proceedings of the Eleventh World Conference on Earthquake Engineering, Acapulco México, 1996.

Pacheco-Martínez, J., Hernandez-Marín, M., Burbey, T. J., González-Cervantes, N., Ortíz-Lozano, J. A., Zermeño-De-Leon, M. E., and Solís-Pinto, A.: Land subsidence and ground failure associated to groundwater exploitation in the Aguascalientes Valley, México, Eng. Geol., 164, 172-186, 2013.

SIFAGG: Sistema de Información de Fallas Geológicas y Grietas, Unpublished results, 2009.

UNAM-SOP: Monitoreo sísmico y análisis estructural de las grietas en la ciudad de Aguascalientes. Informe técnico preparado por el Instituto de Ingeniería de la UNAM para la Secretaria de Obras Públicas del estado de Aguascalientes. Internal project No. 142/93, Unpublished results, Aguascalientes, México, 1994. 